\title{
Sensory neurons in the spinal cord of nominal female embryos in the marine turtle Lepidochelys olivacea respond to shifts in incubation temperature: implications for temperature dependent sex determination
}

\author{
Francisco Jiménez-Trejo ${ }^{1}$, Leonora Olivos-Cisneros ${ }^{2}$, Julieta Mendoza-Torreblanca ${ }^{3}$, Sofía \\ Díaz-Cintraa ${ }^{4}$, Esperanza-Meléndez-Herrera ${ }^{5}$, Armida Báez-Saldaña ${ }^{2}$, Patricia Padilla Cortés ${ }^{6}$, \\ Gabriel Gutiérrez-Ospina², Alma Lilia Fuentes-Farías ${ }^{5 *}$
}

\footnotetext{
${ }^{1}$ Departamento de Biología, Facultad de Química, Universidad Nacional Autónoma de México, México D.F., México 04510;

${ }^{2}$ Departamento de Biología Celular y Fisiología, Instituto de Investigaciones Biomédicas, Universidad Nacional Autónoma de México, México D.F., México 04510;

${ }^{3}$ Departamento de Neuroquímica, Instituto Nacional de Pediatría, México, DF., México 04530;

${ }^{4}$ Departamento de Neurobiología del Desarrollo y Neurofisiología, Instituto de Neurobiología, Universidad Nacional Autónoma de México, Campus UNAM-Juriquilla, Juriquilla, Querétaro México AP.1-1141;

${ }^{5}$ Laboratorio de Invertebrados y Ecofisiología Animal, Facultad de Biología, Universidad Michoacana de San Nicolás de Hidalgo, Morelia, Michoacán, México 58040;

${ }^{6}$ Unidad de Cromatografía Líquida de Alta Resolución, Instituto de Investigaciones Biomédicas, Universidad Nacional Autónoma de México, México D.F., México 04510.

Email:*afuentes@zeus.umich.mx
}

Received 22 November 2010; revised 30 November 2010; accepted 3 December 2010.

\begin{abstract}
Gonadal determination in marine turtles depends on incubation temperature. The mechanisms that spark off this process remain unclear. Previously, we proposed that sensory nerves reaching the gonadal primordium in nominal female embryos of Lepidochelys $(L)$ olivacea may sense and signal incubation temperature. These nerves could later trigger ovarian determination by releasing neurotransmitters in a code constructed based on the thermal information (Gutierrez-Ospina et al., Acetylcholinesterase-positive innervation is present at the undifferentiated stages of the sea turtle Lepidochelys olivacea embryo gonads: implications for temperature-dependent sex determination, J. Comp. Neurol. 410 (1999) 90-98). The hypothesis briefly described, however, has been recently refuted under weak theoretical grounds and experimental misinterpretations (see introduction). Here, we present preliminary results that show that nominal female embryos have sensory neurons located in the dorsal horn laminae I and II of the lumbar spinal cord that display increased c-Fos-like immuno-staining after being incubated either at $15^{\circ} \mathrm{C}$ or $50^{\circ} \mathrm{C}$. Because these spinal neurons are the primary central target of dorsal root ganglion neurons that
\end{abstract}

innervate the urogential crest, these observations keep open the possibility that gonadal sensory nerves indeed signal thermal information that could later be used to trigger or instruct ovarian specification in marine turtles.

Keywords: Reptiles; Ovarian Determination; c-Fos; Incubation Temperature; Sensory Neurons

\section{INTRODUCTION}

Sex determination in marine turtles depends on incubation temperature [1]. In general, low $\left(26-27^{\circ} \mathrm{C}\right)$ or high $\left(32-33^{\circ} \mathrm{C}\right)$ incubation temperatures give rise to males or females, respectively $[2,3]$. Sexual differentiation may be re-directed if eggs are switched from one incubation temperature to the other during the thermo-sensitive period of sex determination [3]. As this period progresses, the effect of shifting the eggs between incubation temperatures on sex determination wanes until fully disappearing [3]. The mechanisms underlying temperature dependent sex determination (TSD) in reptilian species have been the subject of intense research and debate over the past several decades. As a result, it is now widely accepted that incubation temperature channels gonadal, and likely other organs [4], determination and/or differentiation in part by regulating the activity of 
steroidogenic enzymes and the local production of sexual steroids [1,5-7]. Also, recent evidence supports that incubation temperature may modulate the expression of sex determining genes in vertebrate species that display TSD [8-11]. In spite of the progress achieved, the mechanism by which thermal information is translated and funneled towards the activation of the genomicbiochemical pathways that ultimately lead to TSD remains elusive (for a critical review see [12].

Three, likely complementary, hypotheses have been put forward to explaining how TSD might be triggered. In one of these scenarios, it is assumed that there are temperature-sensitive promoters that induce or repress the expression of gonadal genes whose products are key regulators of the gene cascades and/or biochemical pathways that determine gonadal fate [1]. Unfortunately, no empirical evidence has been published so far supporting this notion [12]. The second hypothesis elaborates on the existence of gonadal biochemical pathways that are rendered sensitive to incubation temperature by means of metabolic intermediaries (e.g., $\mathrm{CO}_{2}$ ) whose cellular concentrations shift depending on the incubation temperature [4]. Although some experimental evidence supports this notion, the fact that the synthesis, degradation and/or the activity of fundamental enzymes may shift rapidly as incubation temperature does it in embryos of poikilothermic species [13-15], suggests that this kind of responses may not be tightly controlled by specific sex-determining molecular cascades [16,17].

The third hypothetical scenario calls for the participation of the nervous system. In this model, temperature responsive sensory nerve fibers located within the gonads could signal thermal information and locally release neurotransmitters after being stimulated [18]; sensory nerves are long known to display efferent functions $[19,20]$. The idea just described has been recently refuted [6-8] based on the observation that isolated cultured $L$. olivacea gonads either maintain or down regulate sox-9 expression when incubated at masculinizing or feminizing temperatures, respectively (although see [21] for conflicting results). We believe, nonetheless, that this conclusion is undermined by observations showing that in some vertebrates 1) nerve fibers and terminals are closely associated with embryonic, ovarian estrogen-producing interstitial cells [22-25]; 2) cultured embryonic gonads retain this innervation for several days after being severed from the central nervous system [24,25]; 3) synaptic terminals remain functional and responsive for several days in vitro after being separated from their neuronal origin specially in turtles [26-28]; 4) neurotransmitter release in isolated terminals is sensitive to temperature [29,30]; and 5) aromatase gene transcription and enzymatic activity may be regulated by cate- cholaminergic, dopaminergic and glutamatergic inputs [31,32].

Hence, in this work we intended to re-open the possibility that gonadal sensory innervation signals thermal information by showing neuronal activation in the dorsal horn of the lumbar spinal cord following thermal stimulation in L. olivacea nominal female embryos before ovarian specification takes place. Nominal female embryos were used because sensory innervation is readily established between the lumbar spinal cord and the urogential before ovarian determination is triggered [18].

\section{MATERIAL AND METHODS}

\subsection{Animals and Tissue Sampling}

The experiments were performed using eggs collected in La Escobilla beach (96²7'16’’W, 1540’36'”N), Oaxaca, México. The eggs were transferred to the laboratory in vermiculite-made artificial nests. Once in the laboratory, a total of 16 eggs were placed in an oven at $33^{\circ} \mathrm{C}$ until the embryos reached the stage 23-24 of development; three embryos taken randomly were used to corroborate the developmental stage based on external morphological features [3]. Then, a group of the eggs was switched from $33^{\circ} \mathrm{C}$ to $15^{\circ} \mathrm{C}(\mathrm{n}=5)$. Other group was changed from $33^{\circ} \mathrm{C}$ to $50^{\circ} \mathrm{C}(\mathrm{n}=5)$ during half an hour and then returned to $33^{\circ} \mathrm{C}$ for 30 minutes. This physiologically meaningful temperature range was defined based upon the discrimination features, the physiological responses and the psychophysical properties of warm and cold receptors in mammals [33], and considering the range of incubation temperature [34] and of the ocean water in which turtles normally navigate [35]. Also, experiments conducted in avian eggs have revealed that one hour of incubation in a temperature different from the standard base line incubation temperature is sufficient to modify various embryonic metabolic parameters [36]. By the end of the 30 minutes re-acclimation period, the embryos of both groups were rapidly dissected and fixed in buffered paraformaldehyde (4\%) at $4^{\circ} \mathrm{C}$ overnight. Control eggs $(n=3)$ were kept at $33^{\circ} \mathrm{C}$ throughout the experiment and their embryos were processed as described before. The following day, the embryos were transferred to a solution containing sucrose $(20 \%)$ at $4^{\circ} \mathrm{C}$ until they sank two days later. The embryos were then embedded in OCT compound, frozen in 2-methyl butane pre-chilled with dry ice and cut $(10 \mu \mathrm{m})$ entirely in a coronal plane using a cryostat. One section every $100 \mu \mathrm{m}$ was sampled and mounted onto gelatin coated slides and process through immunofluorescence (see below). In addition, a batch of hatchlings $(n=3)$ was used to collect brain samples for testing the specificity of the antibody through western blot analyses. 


\subsection{Western Blot and Antibody Specificity}

L. olivacea hatchlings (10 days old) were euthanized with pentobarbital (45mg / Kg of body weight) and decapitated. The forebrain was rapidly dissected and placed into microcentrifuge tube containing RIPA buffer (25 mM Tris $\bullet \mathrm{HCl}, 150 \mathrm{mM} \mathrm{NaCl}, 1 \% \mathrm{NP}-40,1 \%$ sodium deoxycholate, $0.1 \%$ SDS, $\mathrm{pH}$ 7.6), supplemented with the complete protease inhibitor cocktail used according to the manufacturer's instructions (Roche Applied Science). The samples were homogenized by sonication (40W) and centrifuged at 12,000 revolutions per minute for 20 minutes at $4^{\circ} \mathrm{C}$. The supernatants were collected and the protein content was estimated by using the bicinchoninic acid protein assay (Pierce) read at 560 nanometers. An aliquote of $75 \mu$ icrograms of protein per sample was electrophoresed through one dimension SDS-polycacrilamide gels (12.5\%) at 150 volts during 90 minutes at $4^{\circ} \mathrm{C}$. Proteins were transferred to nitrocellulose membranes using a semi-dry system (BioRad) during 50 minutes at $0.3 \mathrm{~A}$ of constant current. The quality of the protein transference was evaluated by using Ponceau's staining. After destaining, nitrocellulose membranes were incubated with blocking solution (5\% nonfat milk, $3 \%$ goat serum, $0.1 \%$ Tween-20 in TBS). The membrane was then incubated with rabbit anti-human c-Fos polyclonal primary antibodies (Santa Cruz sc-52) overnight at room temperature (1:200 in blocking solution). This antibody recognizes a highly conserved amino-terminal sequence of c-Fos (residues 4-17) that appear to be present in turtles and amphibians $[37,38]$. After a gently wash in TBS added with $0.1 \%$ Tween-20, the membranes were incubated with the corresponding biotin-conjugated secondary antibody (AP187B, Chemicon) during 2 hours (1:800 in blocking solution) at room temperature. Then, the membranes were washed and incubated with avidin-peroxidase for 1 hour at room temperature following the supplier's recommendations (Vector Laboratories). Peroxidase activity was revealed using a chemo-luminescent substrate according to the manufacturer's guidelines (Immobilon Western, Millipore) and documentation was performed using the Gel Logic 1500 system (Kodak Molecular Imaging).

\subsection{Immunofluorescence}

Tissue sections were incubated with blocking serum containing bovine albumin (1\%) and triton X-100 (0.3\%) in phosphate buffer $(0.1 \mathrm{M}, \mathrm{pH} 7.4)$ for 3 hours at room temperature. After three 15 minute washes, the sections were incubated with primary antibodies raised against c-Fos diluted 1:1000 in blocking serum at $4^{\circ} \mathrm{C}$ for 12 hours. After three washes, the sections were incubated with a secondary antibody goat anti-rabbit IgG coupled to fluorescein diluted 1:200 in blocking serum for three hours at room temperature. The incubation with the primary antibody was omitted in control experiments to rule out false positive results. Following the last washing step, sections were coverslipped with anti-fading mounting medium (Dako). Slides were then observed in an Optiphot Nikon epifluorescence microscope and digital images were taken using a Nikon coolpix digital camera. Figures showing immunocytochemical and western blot results were elaborated by using Adobe Photoshop CS2 (version 9.0.2).

\section{RESULTS}

\subsection{Antibody Specificity}

Figure 1 illustrates a representative Western blot showing the single protein band that was immuno-reactive for c-Fos in samples of the $L$. olivacea hatchlings forebrain. Such a band displayed an approximate molecular weight of $40 \mathrm{kDa}$, a weight that is similar to that published for one of the c-Fos nuclear isoforms reported in the frog Rana esculenta [38].

\subsection{Spinal Cord c-Fos Immunoreactivity}

Once established the specificity of the antibodies based on molecular weight equivalence, we evaluated whether the intensity and location of c-Fos-like immuno-staining shifted in neurons located in the dorsal horn of the embryonic lumbar spinal cord at the ontogenetic stage 23-24, before ovarian specification occurs [3]; these spinal

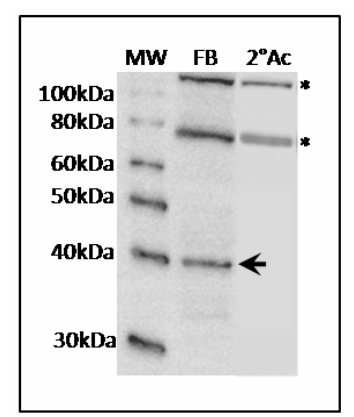

Figure 1. Digital image of a representative western blot stained for c-Fos obtained after running samples obtained from the $L$. olivacea hatchlings forebrain. Lane 1: MW-Molecular Weight Delete the dash in molecular markers; Lane 2: FB-Forebrain samples; Lane 3: Background staining associated with the secondary antibody (asterisks; $2^{\circ}$ $\mathrm{AC}$ ). The arrow indicates where the c-Fos immunoreactive band is identified. 
neurons are the primary central target of dorsal root ganglion neurons that innervate the urogential crest [18]. Two patterns of cellular staining were consistently observed. Embryos exposed to $15^{\circ} \mathrm{C}$ had neurons exhibiting cytoplasmic staining (Figure 2(a)). In contrast, when embryos were exposed to $50^{\circ} \mathrm{C}$, the majority of neurons displayed nuclear staining (Figure 2(b)). In our hands, embryos kept at their original incubation temperature did not show appreciable expression of c-Fos in the spinal cord (Figure 2(c)). Omission of the primary antibody resulted in a negative c-Fos immunostaining (not shown). Finally, even though the pattern of cytological staining differed between embryos exposed to high or low incubation temperatures, the distribution and relative amount of immunopositive neurons was similar between groups; numerous c-Fos like immunopositive neurons essentially occupied laminae I and II of the dorsal horn at the lumbar segments of the spinal cord.

\section{DISCUSSION}

Sex determination in marine turtles depends on incuba tion temperature. Although the molecular and biochemi-

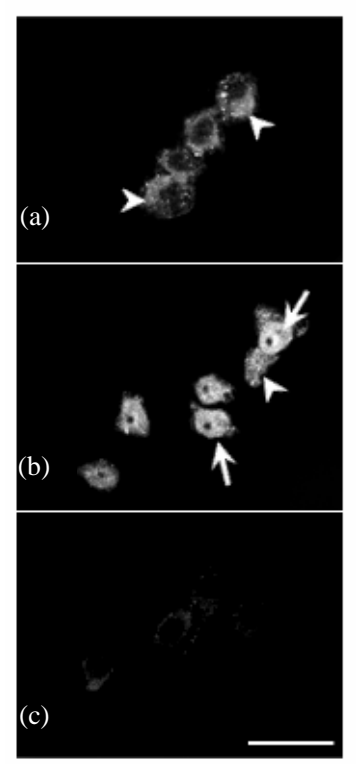

Figure 2. Digital photomicrographs showing examples of the cellular patterns observed for c-Fos staining in the dorsal horn of the spinal cord following the exposure of embryos at $15^{\circ} \mathrm{C}$ (a) or $50^{\circ} \mathrm{C}$ (b). Nuclear (arrows) and cytoplasmic (arrowheads) staining are indicated. (c) Illustrates c-Fos basal staining in the spinal cord of non-stimulated embryos. Scale Bar $=10 \mu \mathrm{m}$. cal processes that channel ovarian and testicular determination during TSD are now better understood, the precise mechanisms by which it is triggered remain unclear. We have previously suggested that sensory nerves located inside the undifferentiated gonad of nominal $L$. olivacea female embryos might signal thermal information and, upon activation, might release neurotransmitters that could turn on the cascade of events leading to sex determination [18]. In this work, we provide evidence that strengthens this possibility by showing that sensory neurons located in the dorsal horn of the lumbar spinal cord respond to shifts in incubation temperature, as monitored by the increment of the staining intensity of a c-Fos-like protein. The spinal levels where c-Foslike positive neurons were mapped precisely in sites that receive primary sensory afferents incoming from the urogenital crest [18]. Because sensory nerves exert efferent functions on their targets $[19,20]$, we believe this primordial connectivity might be an important component of the machinery triggering ovarian differentiation, even in the absence of activation of upper neural structures involved in thermal information processing.

In spite of the implications that our results have on TSD conceptions, we must be prudent in interpreting the present data. Given the protocol used for eliciting neuronal activation, we cannot rule out that the increment in the intensity of c-Fos like immuno-staining observed in spinal cord sensory neurons might in part reflect heat stress-associated responses; this distinction may be crucial because c-Fos may exert pro-apoptotic actions [39]. However, in favor of our experimental design 1) it has been documented that increments of c-Fos availability can also counteract apoptosis and promote cell differentiation [40]; 2) Also increment in c-Fos availability and nuclear translocation facilitates cell proliferation [41]; 3) The thermal values used to stimulate the embryos were carefully selected based on what we know on the discrimination features, physiological properties and psychophysical responses of warm and cold receptors in mammals, the best characterized receptors in the animal kingdom [33]. We also considered the temperature range of the nests [e.g., 34] and of the ocean water in which marine turtles normally navigate [35]. Even so, we would concord that a definitive answer requires an unquestionable molecular identification of the neuronal phenotype that is involved specifically in thermal information processing in marine turtle embryonic spinal cord, as it has been shown for central neurons in Caenorhabditis elegans based on LIM homeobox gene expression [42].

An intriguing observation is related with the differential distribution of c-Fos inmunostaining in the cytoplasm or nuclear compartments of the activated spinal 
cord neurons, depending on the temperature under which the embryos were incubated. Indeed, cytoplasmic staining was consistently observed in embryos incubated at $15^{\circ} \mathrm{C}$, whereas nuclear staining was observed in those kept at $50^{\circ} \mathrm{C}$. Although this result could be considered as irrelevant or even art factual, c-Fos-like cytoplasmic and/or nuclear staining following neuronal activation is not uncommon in phyla different from mammals [38, 41,43-47]. Indeed, it has been shown that c-Fos cytoplasmic staining reflects a reduced rate of translocation to the nucleus due to decreased metabolic rates [41,44], increased phospholipid metabolism [47] or diminished hormonal stimulation [38]. Further studies are necessary to explore each one of these possibilities.

\section{ACKNOWLEDGEMENTS}

Authors thank to Luz Lilia Jiménez Rico, Jesús Ramírez-Santos, Martha Carrasco and Raymundo Reyes for their technical expertise and guidance and for administrative support. We are also indebted to Alejandro Marmolejo for his professional advice in eggs' care and handling. Authors are grateful to Dr. David Riddle for careful editing and helpful criticisms. LOC and EMH are holders of scholarships from the Consejo Nacional de Ciencia y Tecnología (CONACyT). This work was supported by grants from CONACyT 82879 and 94312 to GGO and CIC UMSNH (8.37) to ALFF.

\section{REFERENCES}

[1] Merchant-Larios, H. (2001) Temperature sex determination in reptiles: The third strategy. Journal of Reproduction and Development, 47, 245-252. doi:10.1262/jrd.47.245

[2] Merchant-Larios, H., Villalpando-Fierro, I. and Centeno-Urquiza, B. (1989) Gonadal morphogenesis under controlled temperature in the sea turtle Lepidochelys olivacea. Herpetological Monographs, 3, 43-61. doi: $10.2307 / 1466985$

[3] Merchant-Larios, H., Ruíz-Ramírez, S., Moreno-Mendoza, N. and Marmolejo-Valencia, A. (1997) Correlation among thermosensitive period, estradiol response, and gonad differentiation in the sea turtle Lepidochelys olivacea. General and Comparative Endocrinology, 107, 373-385. doi:10.1006/gcen.1997.6946

[4] Jeyasuria, P. and Place, A.R. (1998) Correlation among thermosensitive period, estradiol response, and gonad differentiation in the sea turtle Lepidochelys olivacea aromatase (CYP19). Journal of Experimental Zoology, 281, 428-449.

doi:10.1002/(SICI)1097-010X(19980801)281:5<428::AI D-JEZ8>3.3.CO;2-4

[5] Bergeron, J.M., Willingham, E., Osborn, C.T., Rhen, T. and Crews, D. (1999) Developmental synergism of steroidal estrogens in sex determination. Enviromental Health Perspectives, 107, 93-97. doi:10.1289/ehp.9910793

[6] Pieau, C. and Dorizzi, M. (2004) Oestrogens and temperature-dependent sex determination in reptiles: all is in the gonads. Journal of Endocrinology, 181, 367-377. doi:10.1677/joe.0.1810367

[7] Ramsey, M. and Crews, D. (2008) Steroid signaling and temperature-dependent sex determination-reviewing the evidence for early action of estrogen during ovarian determination in turtles. Seminars in Cell \& Developmental Biology, 20, 283-292. doi:10.1016/j.semcdb.2008.10.004

[8] Moreno-Mendoza, N., Harley, V.R. and Merchant-Larios, H. (2001) Temperature regulates SOX9 expression in cultured gonads of Lepidochelys olivacea, a species with temperature sex determination. Developmental Biology, 229, 319-326. doi:10.1006/dbio.2000.9952

[9] Sarre, S.D., Georges, A. and Quinn, A. (2004) The ends of a continuum: genetic and temperature-dependent sex determination in reptiles. BioEssays, 26, 639-645. doi:10.1002/bies.20050

[10] Shoemaker, C.M. and Crews, D. (2009) Analyzing the coordinated gene network underlying temperature-dependent sex determination in reptiles. Seminars in Cell \& Developmental Biology, 20, 293-303. doi:10.1016/j.semcdb.2008.10.010

[11] Torres-Maldonado, L.C. and Merchant-Larios, H. (2006) Aspectos moleculares de la determinacion del sexo en tortugas. Ciencia Ergo Sum, 13, 176-182.

[12] Lance, V.A. (2009) Is regulation of aromatase expression in reptiles the key to understanding temperature-dependent sex determination? Journal of Experimental Zoology, 311, 314-322. doi:10.1002/jez.465

[13] Lundquist A., Lowkvist B., Linden M. and Heby 0. (1983) Polyamines in early embryonic development: their relationship to nuclear multiplication rate, cell cycle traverse, and nucleolar formation in a dipteran egg. Developmental Biology, 95, 253-259. doi:10.1016/0012-1606(83)90026-X

[14] Manen, C.A. and Russell, D.H. (1973) Early cyclical changes in polyamine synthesis during sea-urchin development. Journal of Embryology \& Experimental Morphology, 30, 243-256.

[15] Neyfakh, A.A., Yarygin, K.N. and Gorgolyuk, S.I. (1983) Ornithine decarboxylase activity in embryos depends on temperature of development rather than on the stage of development. Biochemistry Journal, 216, 597-604.

[16] Penick, N.D., Paladino, V.F., Steyermurk, C.A. and Spotila, R.J. (1996) Thermal dependence of tissue metabolism in the green turtle, Chelonia mydas. Comparative Biochemistry and Physiology, 113, 293-296. doi:10.1016/0300-9629(95)02068-3

[17] Seebacher, F. and Franklin, C.E. (2005) Physiological mechanisms of thermoregulation in reptiles: a review. Journal of Comparative Physiology B: Biochemical, Systemic, and Environmental Physiology, 175, 533-541. doi:10.1007/s00360-005-0007-1

[18] Gutiérrez-Ospina, G., Jiménez-Trejo, F.J., Favila, R., Moreno-Mendoza, N., Granados-Rojas, L., Barrios, F.A. and Merchant-Larios, H. (1999) Acetylcholinesterasepositive innervation is present at the undifferentiated stages of the sea turtle Lepidochelys olivacea embryo gonads: Implications for temperature-dependent sex determination. The Journal of Comparative Neurology, 410, 90-98.

doi:10.1002/(SICI)1096-9861(19990719)410:1<90::AID -CNE8>3.0.CO;2-7

[19] Maggi, C.A. (1991) The pharmacology of the efferent 
function of sensory nerves. Journal of Autonomic Pharmacology, 11, 173-208.

doi:10.1111/j.1474-8673.1991.tb00317.x

[20] Martínez-Martínez, E., Toscano-Márquez, B. and Gutiérrez-Ospina, G. (2010) Long-term effects of neonatal capsaicin treatment on intraepidermal nerve fibers and keratinocite proliferation in rat glabrous skin. The Anatomical Record Journal, in press.

[21] Merchant-Larios H. and Villalpando I. (1990) Effect of temperature on gonadal sex differentiation in the sea turtle Lepidochelys olivacea: An organ culture study. Journal of Experimental Zoology, 254, 327-331. doi:10.1002/jez.1402540312

[22] Amanuma, A. and Yamada, K. (1979) Innervation of the ovarian interstitial cell of the chick embryo. Experientia, 35, 403-406. doi:10.1007/BF01964378

[23] Ávila, R.E., Samar, M.E. and Fabro, S.P. (1991) Interstitial cells of the ovaries of the chick embryo: Ultrastructural aspects of their innervations. Revista de la Facultad de Ciencias Médicas, Universidad Nacional de Córdoba, República Argentina, 49, 13-17.

[24] Ávila, R.E., Samar, M.E., Ferraris, R. and Bonomi, L. (2001) Ultrastructural behavior of interstitial cells innervation during differentiation of the chick embryo ovary cultured with 17-beta-estradiol. Revista de la Facultad de Ciencias Médicas, Universidad Nacional de Córdoba, República Argentina, 58, 49-55.

[25] Ávila R.E., Samar M.E., Ferraris R. and Centurion C., (2002) Subcellular aspects of interstitial cell innervation in chick embryo ovary cultured with LH or hCG. Revista de la Facultad de Ciencias Médicas, Universidad Nacional de Córdoba, República Argentina, 59, 63-69.

[26] Edwards R.A., Lutz P.L. and Baden D.G. (1989) Relationship between energy expenditure and ion channel density in the turtle and rat brain," American Journal of Physiology, Regulatory, Integrative and Comparative Physiology, I, 257, 1354-1358.

[27] Milton, S.L. (1994) The physiology of hypoxia and anoxia tolerance in three species of turtle: The loggerhead sea turtle (Caretta caretta), green sea turtle (Chelonia mydas) and freshwater Trachemys scripta. Ph. D. dissertation, University of Miami.

[28] Greenway S.C. and Story K.B., (1999) Mitogen-activated protein kinases and anoxia tolerance in turtles. Journal of Experimental Zoology, 287, 477-484. doi:10.1002/1097-010X(20001201)287:7<477::AID-JEZ 3>3.0.CO;2-4

[29] Pockett, S. and MacDonald, J.A. (1986) Temperature dependence of neurotransmitter release in the antarctic fish Pagolthenia borchgrevinki. Experientia, 42, 414-415. doi:10.1007/BF02118635

[30] Yang, X.F., Ouyang, Y., Kennedy, B.R. and Rothman, S.M. (2005) Cooling blocks rat hippocampal neurotransmission by a presynaptic mechanism: Observations using 2-photon microscopy. The Journal of Physiology, 567, 215-224. doi:10.1113/jphysiol.2005.088948

[31] Baillien, M., and Balthazart, J.A. (1997) Direct dopaminergic control of aromatase activity in the quail preoptic area. The Journal of Steroid Biochemistry and Molecular Biology, 63, 99-113. doi:10.1016/S0960-0760(97)00080-0

[32] Absil, P., Baillien, M., Ball, F.G., Panzica, G.C. and
Balthazart, J. (2001) The control of preoptic aromatase activity by afferent inputs in japanese quail. Brain Research Reviews, 37, 38-58. doi:10.1016/S0165-0173(01)00122-9

[33] Patapoutian, A., Peier, M.A., Story, M.G. and Viswanath, V. (2003) ThermoTRP channels and beyond: mechanisms of temperature sensation. Nature Reviews, Neuroscience, 4, 529-539. doi:10.1038/nrn1141

[34] Mrosovsky, N. (1994) Sex ratios of sea turtles. The Journal of Experimental Zoology, 270, 16-27. doi:10.1002/jez.1402700104

[35] Coles, C.W. (1999) Aspects of the biology of sea turtles in the mid Atlantic bight. PhD. Dissertation. Faculty of the School of Marine Science, William and Mary College, Virginia.

[36] Lourens, A., Van den Brand, H., Heetkamp, M.J.W., Meijerhof, R. and Kemp, B. (2006) Metabolic responses of chick embryos to short-term temperature fluctuations. Poultry Sciences, 85, 1081-1086.

[37] Yaqub, A., Guimaraes, M. and Eldred, D.W. (1995) Neurotransmitter modulation of Fos and Jun-like proteins in the turtle retina. The Journal of Comparative Neurology, 354, 481-500. doi:10.1002/cne.903540402

[38] Cobellis, G., Meccariello, R., Minucci, S., Palmiero, C., Pierantoni, R. and Fasano, S. (2003) Cytoplasmic Versus Nuclear localization of fos-related proteins in the frog, Rana esculenta, testis: In Vivo and direct In Vitro effect of a gonadotropin-releasing hormone agonist1. Biology of Reproduction, 68, 954-960. doi:10.1095/biolreprod.102.008938

[39] Hafezi, F., Steinbach, J.P., Marti, A., Munz, K., Wang, Z.-Q., Wagner, E.F., Aguzzi, A. and Remé, C.E. (1997) The absence of c-fos prevents light-induced apoptotic cell death of photoreceptors in retinal degeneration in vivo. Nature Medicine, 3, 346-349. doi:10.1038/nm0397-346

[40] Schreiber, M., Baumann, B., Cotton, M., Angel, P. and Wagner, E.F. (1995) Fos is an essential component of the mammalian UV response. The EMBO Journal, 14, 53385349.

[41] Cobellis, G., Meccariello, R., Fienga, G., Pierantoni, R. and Fasano, S. ( 2002) Cytoplasmic and nuclear fos protein forms regulate resumption of spermatogenesis in the frog, Rana esculenta. Endocrinology, 143, 163-170. doi:10.1210/en.143.1.163

[42] Hobert, O., Alberti, T.D., Liu, Y. and Ruvkun, G. (1998) Control of neural development and function in a thermoregulatory network by the LIM homeobox gene lin- 11 . The Journal of Neuroscience, 18, 2084-2096.

[43] Bosch, T.J., Madam, S. and Roberts, B.L. (1995) A polyclonal antibody against mammalian FOS can be used as a cytoplasmic neuronal activity marker in a teleost fish. Journal of Neurosciences Methods, 58, 173-179. doi:10.1016/0165-0270(94)00174-F

[44] Bosch, T.J., Madam, S. and Roberts, B.L. (2001) Fos-like immunohistochemical identification of neurons active during the startle response of the Rainbow Trout. The Journal of Comparative Neurology, 439, 306-314.

[45] Roux, P., Blanchard, J.M., Pernandez, A., Lamb, N., Jeanteur, P. and Piechaczyk, M. (1990) Nuclear localization of c-Fos, but not v-Fos proteins, is controlled by extracellular signals. Cell, 63, 341-351. 
[46] Salierno, J.D., Snyderb, N.S., Murphyc, A.Z., Polid, M. Halle, S., Badenf, D. and Kanea, S. (2006) Harmful algal bloom toxins alter c-Fos protein expression in the brain of killifish, Fundulus heteroclitus. Aquatic Toxicology, 78, 350-357. doi:10.1016/j.aquatox.2006.04.010
[47] Bussolino, D.F., Guido, M.E., Gil, G.A., Borioli, G.A., Renner, M.L, Grabois, V.R, Conde, C.B. and Caputto, B.L. (2001) c-Fos associates with the endoplasmic reticulum and activates phospholipid metabolism. The FASEB Journal, 15, 556-558. 